\title{
Long-term Effect and Predictive Factors of Motor Cortex and Spinal Cord Stimulation for Chronic Neuropathic Pain
}

\author{
Takafumi TANEI, ${ }^{1}$ Yasukazu KAJITA, ${ }^{2}$ Satoshi MAESAWA, ${ }^{3}$ Daisuke NAKATSUBO, ${ }^{3}$ \\ Kosuke AOKI, ${ }^{3}$ Hiroshi NODA, ${ }^{4}$ Shigenori TAKEBAYASHI, ${ }^{1}$ Norimoto NAKAHARA, ${ }^{1}$ \\ and Toshihiko WAKABAYASHI ${ }^{3}$
}

\begin{abstract}
${ }^{1}$ Department of Neurosurgery, Nagoya Central Hospital, Nagoya, Aichi, Japan;
${ }^{2}$ Department of Neurosurgery, Nagoya Medical Center, Nagoya, Aichi, Japan;

${ }^{3}$ Department of Neurosurgery, Nagoya University Graduate School of Medicine, Nagoya, Aichi, Japan;

${ }^{4}$ Department of Neurosurgery, Iwakura Hospital, Iwakura, Aichi, Japan
\end{abstract}

\begin{abstract}
The long-term effects of motor cortex stimulation (MCS) and spinal cord stimulation (SCS) remain unknown. To identify the long-term effects after MCS or SCS and determine any associated predictive factors for the outcomes. Fifty patients underwent MCS $(n=15)$ or SCS $(n=35)$ for chronic neuropathic pain. The degree of pain was assessed preoperatively, at 1, 6, and 12 months after surgery, and during the time of the last follow-up using Visual Analog Scale (VAS). Percentage of pain relief (PPR) was calculated, with "long-term effect" defined as PPR $\geq 30 \%$ and the presence of continued pain relief over 12 months. Outcomes were classified into excellent (PPR $\geq 70 \%$ ) and good (PPR 30-69\%) sub-categories. Long-term effects of MCS and SCS were observed in $53.3 \%$ and $57.1 \%$ of the patients, respectively. There were no predictive factors of long-term effects identified for any of the various preoperative conditions. However, the VAS at 1 month after surgery was significantly associated with the long-term effects in both MCS and SCS. All patients with an excellent outcome at 1 month after the surgery continued to exhibit these effects. In contrast, patients with the good outcome at 1 month exhibited a significant decrease in the effects at 6 months after surgery. The long-term effects of MCS and SCS were approximately $50 \%$ during the more than 8.5 and 3.5 years of follow-up, respectively. The VAS at 1 month after surgery may be a postoperative predictor of the long-term effects for both MCS and SCS.
\end{abstract}

Key words: long-term, motor cortex stimulation, neuromodulation, neuropathic pain, spinal cord stimulation

\section{Introduction}

Neuropathic pain is caused by lesions in the somatosensory pathway in the peripheral or central nervous system. A change in the activation of the pain matrix is thought to be one of the mechanisms responsible for the pathogenesis of neuropathic pain. ${ }^{1)}$ The pain matrix consists of a network of brain structures that include areas such as the thalamus, anterior cingulate cortex, and somatosensory cortices, among other regions. Since most neuropathic pain patients do not respond sufficiently to

Received April 17, 2018; Accepted July 10, 2018

Copyright $\odot 2018$ by The Japan Neurosurgical Society This work is licensed under a Creative Commons AttributionNonCommercial-NoDerivatives International License. medical treatment, non-medical approaches such as neuromodulation therapies have been developed. The main neuromodulation therapies currently being used for chronic neuropathic pain include motor cortex stimulation (MCS) and spinal cord stimulation (SCS).

MCS was first proposed for the treatment of central poststroke pain (CPSP). ${ }^{2,3)}$ Subsequently, several case series have reported on the efficacy of MCS for multiple types of pain including trigeminal neuropathic pain, phantom limb pain, and spinal cord injury (SCI) pain..$^{4-11)}$ Four randomized controlled trials with a crossover design have been published. ${ }^{12-15)}$ SCS has now become the most widely used neuromodulation therapy due to the less invasiveness, low complication rate, and effectiveness. ${ }^{16,17)}$ Other reasons for the increased use 
of SCS instruments include improvements in the devices. ${ }^{18,19)}$ The efficacy of SCS for particular types of peripheral neuropathic pain has been demonstrated by randomized controlled trials examining failed back surgery syndrome (FBSS), ${ }^{20,21)}$ complex regional pain syndrome (CRPS) type $\mathrm{I},{ }^{22)}$ painful diabetic neuropathy, ${ }^{23,24)}$ and angina pectoris. ${ }^{25)}$

Although neuromodulation therapies are performed throughout the world to treat various chronic neuropathic pains, predictive factors for the long-term effects have yet to be established. While it has been documented that patients do express dramatic pain relief after undergoing neuromodulation therapy, it remains unclear as to the mechanism responsible for bringing about the dramatic pain relief. The aim of this study was to evaluate the rates of the long-term effects and the predictive factors associated with the long-term effects in both MCS and SCS, and the differences between the dramatic and moderate pain relief in both MCS and SCS.

\section{Methods}

\section{Patients and methods}

This study was a retrospective review of 50 consecutive patients who underwent surgical implantation of MCS or SCS electrodes for the treatment of chronic neuropathic pain by the Functional Neurosurgery Team of Nagoya University. Procedures were performed at either the Nagoya University Hospital or Nagoya Central Hospital in Japan from 1999 to 2016. All patients exhibited a poor response to medications before surgery. MCS was performed from 1999 to 2009. Since 2010, the eight-contact electrodes and an implantable pulse generator stimulating 16 contacts became available for clinical use in Japan. Then, we select SCS for patients who presented with lumbar, upper, or lower extremity pain. Only when the patient presented with facial pain, we select MCS. Patients found to have severe depression, psychiatric disorders, drug abuse, or who did not have a sufficient ability to communicate due to severe neurological deficits were excluded from the analysis. The study protocol was approved by the local ethics committees of the Nagoya University Hospital and Nagoya Central Hospital. All patients were informed about the procedure and provided written informed consent prior to the start of the study.

\section{Patients who underwent MCS/SCS electrode implantation}

Fifteen patients underwent implantation of MCS electrodes. The mean age \pm standard deviation was $56.1 \pm 13.6$ years. The preoperative mean duration of pain was $3.5 \pm 2.3$ years. Patients were classified according to the anatomical location of lesion as follows: central pain of brain $(n=9)$, central pain of spinal cord $(n=2)$, and peripheral neuropathic pain $(n=3)$. Causes of pain included CPSP $(n=9)$, SCI $(n=2)$, peripheral neuropathy $(n=3)$, and other causes $(n=1)$. Sites of pain were upper extremity $(n=3)$, lower extremity $(n=1)$, upper and lower extremities $(n=8)$, and face $(n=3)$. Table 1 summarizes the clinical features and outcomes of the patients who underwent MCS.

Thirty-five patients underwent implantation of SCS electrodes. The mean age of the patients was $63.4 \pm 12.2$ years. The preoperative mean duration of pain was $4.4 \pm 3.7$ years. Patients were classified according to the anatomical location of lesion as follows: central pain of brain $(n=18)$, central pain of spinal cord $(n=4)$, and peripheral neuropathic pain $(n=13)$. Causes of pain were CPSP $(n=17)$, FBSS $(n=7)$, SCI $(n=4)$, peripheral neuropathy $(n=3)$, CRPS type I $(n=1)$, and other causes $(n=3)$. Sites of pain were upper extremity $(n=5)$, lower extremity $(n=9)$, upper and lower extremities ( $n=13)$, lumbar $(n=3)$, lumbar and lower extremity $(n=4)$, and other $(n=1)$. Table 2 summarizes the clinical features and outcomes of the patients who underwent SCS.

\section{MCS electrode implantation procedures}

A preoperative magnetic resonance image was taken after placement of fiducial markers. After using a preliminary target to calibrate the image-guided navigation system, a skin incision and one burr hole around the central sulcus were made under local anesthesia. A six-plate electrode array was inserted from the edge of the burr hole into the epidural space, with the locations of the precentral and postcentral gyri confirmed by the phase reversal of the N20 wave of the somatosensory evoked potential recorded by median nerve stimulation. A four-plate electrode array (3587A Resume II; Medtronic Inc., Minneapolis, MN, USA) was inserted into the pain site target on the precentral gyrus, with muscle contraction of the pain area through bipolar stimulation via the electrodes used to confirm the location.

\section{SCS electrode implantation procedures}

After each patient was placed in the prone position, the 18-gauge Tuohy needle was inserted into the midline epidural space under local anesthesia. Four-contact electrodes (Pisces Quad, Model 3487A; Medtronic Inc.) were inserted in the initial four subjects. Once the eight-contact electrodes and an implantable pulse generator became available for clinical use, we began inserting the eight-contact 


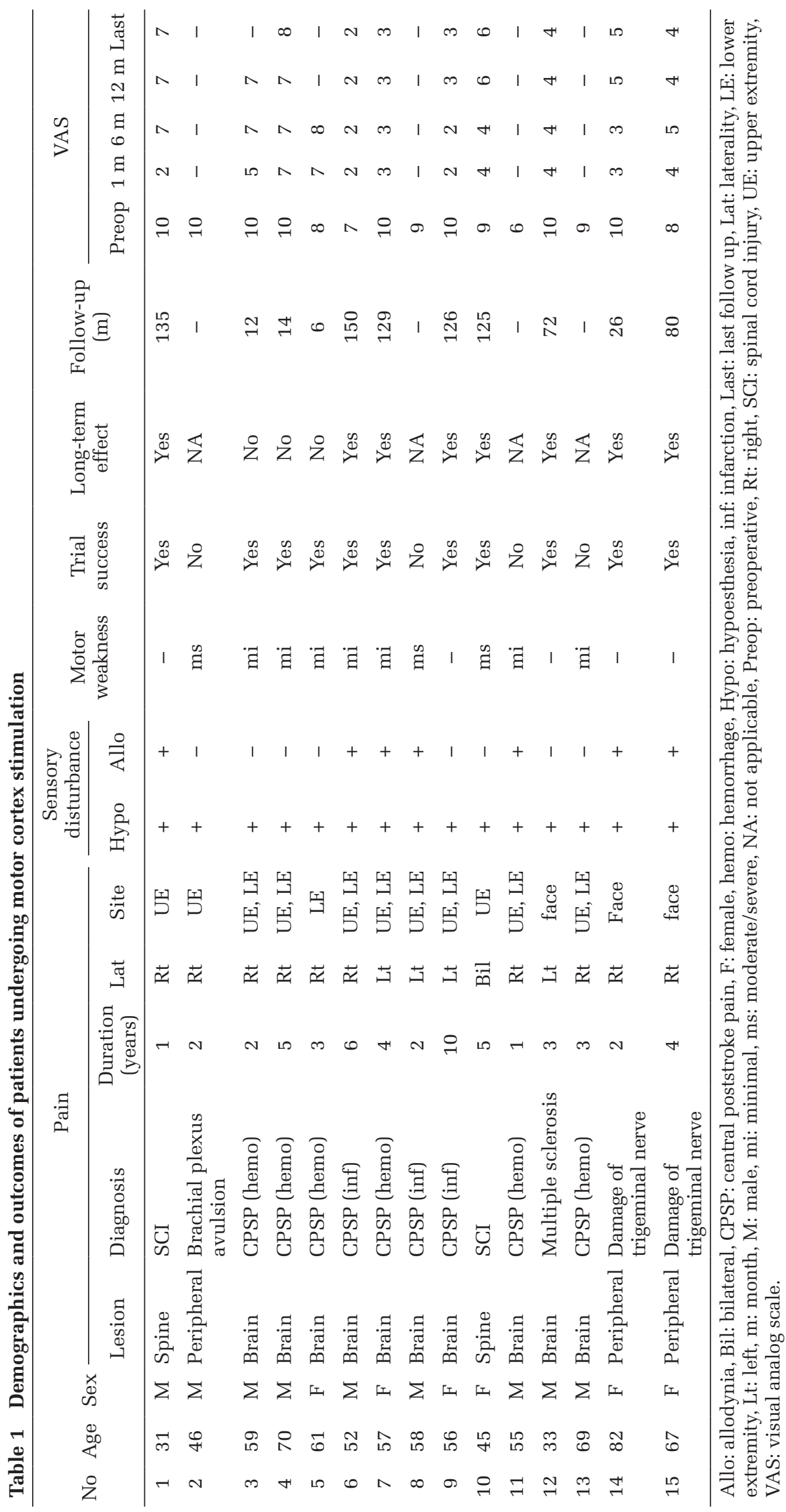

Neurol Med Chir (Tokyo) 58, October, 2018 


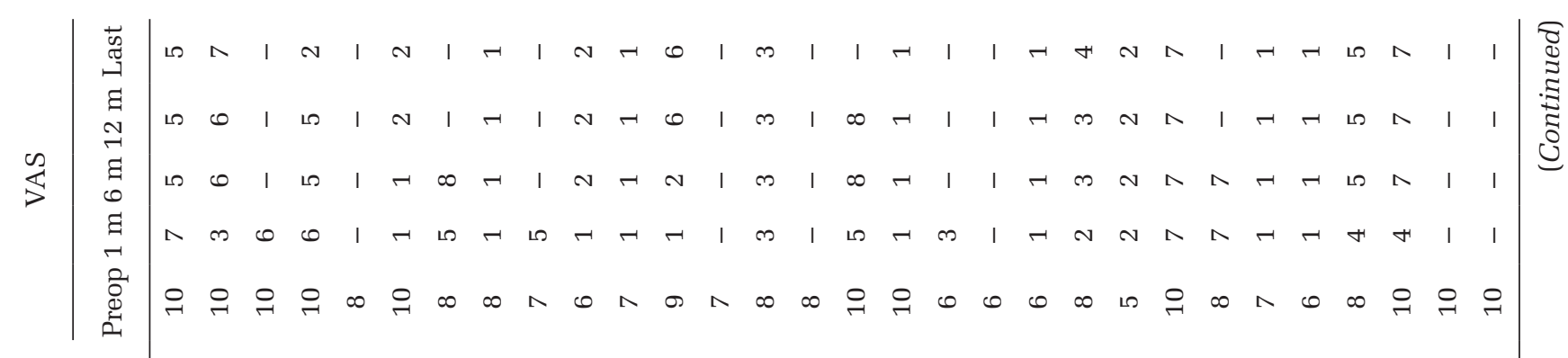

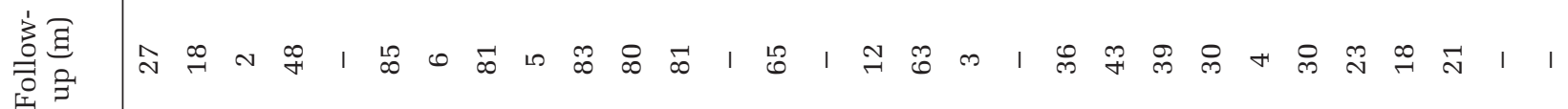
章苞 .

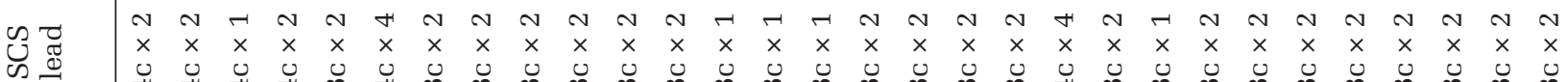

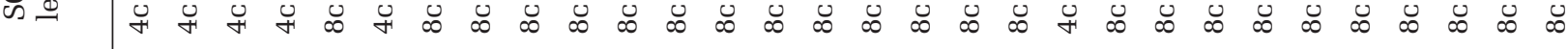
刨莺

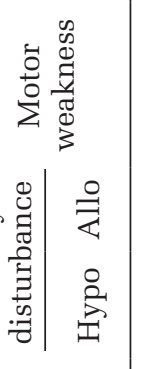

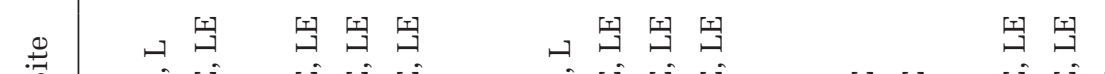
। 灵

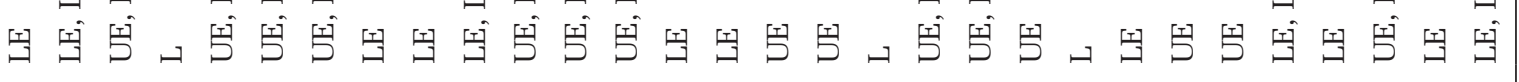

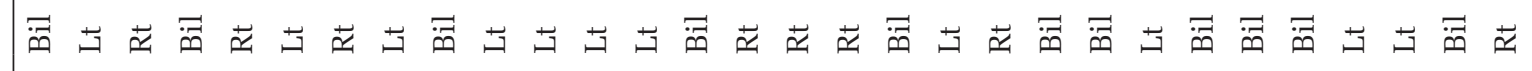
รี क $-$

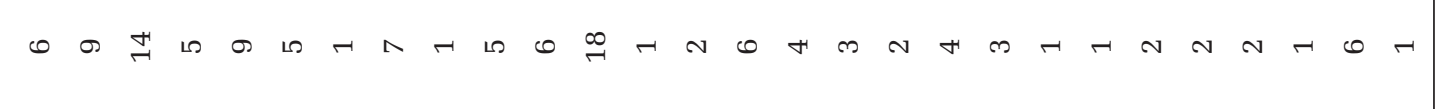

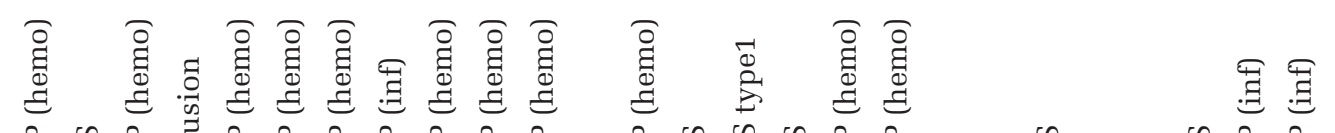

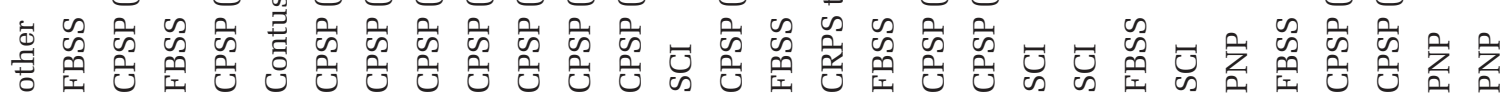
焉莺

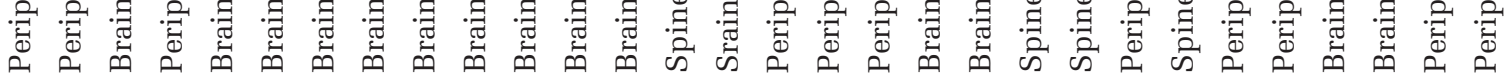

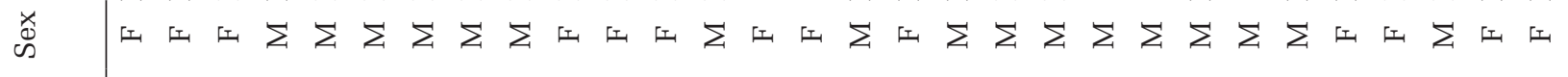
道

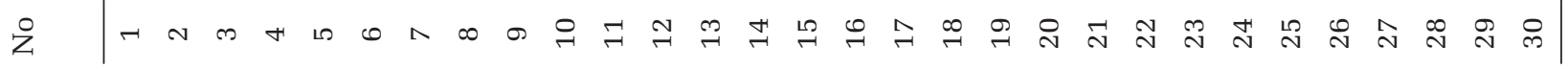




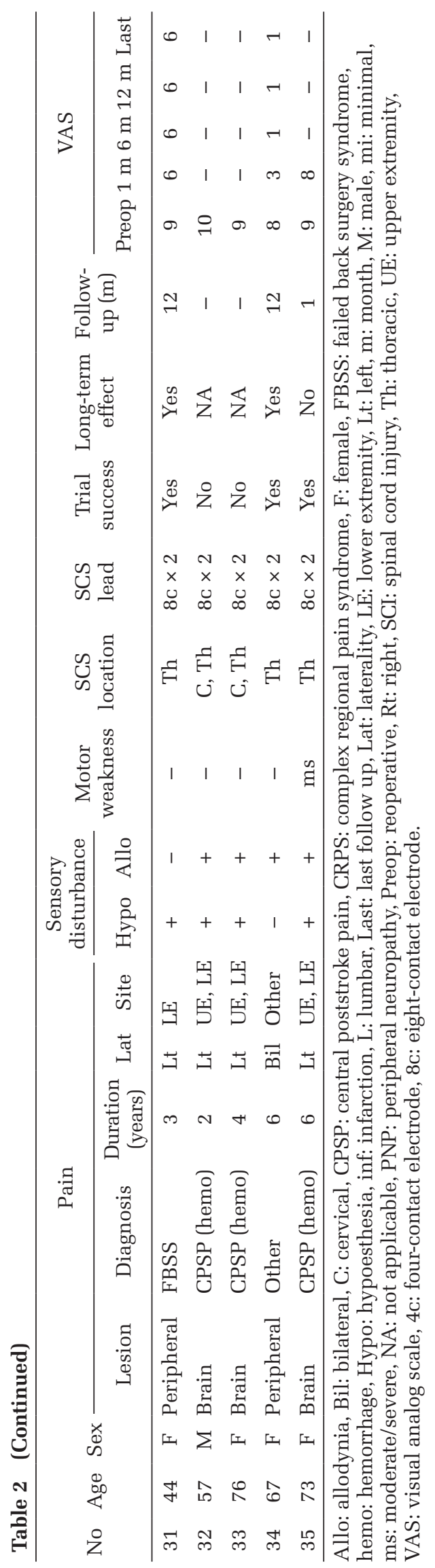

electrode (Octad Lead Standard, Model 3777, Vectris SureScan MRI Compact, Model 977A2; Medtronic Inc.). For dual-lead SCS, two electrodes were placed in parallel. In two subjects, we employed 4 fourcontact electrodes. When insertion of two electrodes was technically difficult, only one electrode was inserted. The electrodes were manipulated using radiographic guidance, with the stimulation-induced paresthesia covering the entire region affected by the pain.

\section{Test stimulation and implantation of the implantable pulse generator}

A test stimulation (= trial) was performed approximately 7 days after the insertion of the MCS or SCS electrodes in order to assess the efficacy and adverse effects. When a reduction of $>50 \%$ was achieved in the VAS, this was defined as a "trial success". If deemed successful, the electrode was then connected to an implantable pulse generator (IPG) under general anesthesia. The MCS electrode was connected to an IPG (Itrel III; Medtronic Inc.). The SCS electrode was connected to an IPG (Synergy, PrimeAdvanced, PrimeAdvanced SureScan MRI or RestoreSensor SureScanMRI; Medtronic Inc.). If the trial was not successful, the electrode and percutaneous extension were removed from the patient.

\section{Assessment}

The degree of pain was assessed using the Visual Analog Scale (VAS). Assessments of pain were performed at the time when it's most painful during 1 day, because the pain fluctuated during 1 day. The preoperative VAS score was used as the baseline. Postoperative outcomes were assessed at 1,6 , and 12 months after the surgery, and at the time of the last follow-up. Percentages of pain relief (PPR) from the preoperative VAS were calculated at 1,6 , and 12 months after the surgery, and at the time of the last follow-up [PPR $(\%)=$ (preoperative VAS - postoperative VAS)/preoperative VAS $\times$ 100]. MCS and SCS outcomes were classified into two sub-categories according to the PPR, with $\geq 70 \%$ indicating an excellent outcome and 30-69\% indicating a good outcome. We defined a successful "long-term effect" as a patient who achieved a PPR $\geq 30 \%$ and who had continuous pain relief over 12 months. Failure was defined as a PPR $<30 \%$ as compared to the baseline. Patients were additionally separated into three groups according to their trial and long-term outcomes as follows: (1) trial success with implantation of the IPG and an observed long-term effect (long-term effect group), (2) trial success with implantation of the IPG, but without any long-term effect (no long-term effect 
group), and (3) the trial was not a success and the IPG was not implanted (no trial success group).

\section{Statistics}

The three trial groups were analyzed by an ANOVA using age, duration of pain, and preoperative VAS scores to compare the preoperative patient conditions for the MCS and SCS. The factors used for the Fisher's exact test included sex, location of lesion, sensory disturbance, motor weakness, site of pain, and laterality of pain. The Fisher's exact test was also used to determine the relationship between the long-term effect of MCS/SCS and the location of lesion. Wilcoxon rank sum test using the postoperative VAS scores at 1, 6, and 12 months after the surgery, and at the time of the last follow-up was performed in order to compare the difference between the long-term effect and the no long-term effect groups of MCS and SCS. The Wilcoxon rank sum test was also performed to compare the difference between the excellent and good groups of MCS and SCS using age, duration of pain, and the preoperative and postoperative VAS scores at 1, 6, and 12 months after the surgery, and at the time of the last follow-up. Fisher's exact test was also used to examine the differences in the sex, location of lesion, sensory disturbance, motor weakness, site of pain, and laterality of pain. Probability values of less than 0.05 were considered statistically significant. To investigate the long-term effect group of SCS, we used the PPR score at 1 month after the surgery. The point with the best sum of sensitivity and specificity for the Youden Index in the receiver operating characteristic (ROC) curve was defined as the cut-off value. We used the "exactRankTests" and "pROC" packages for the Wilcoxon rank sum test analysis and ROC analysis, respectively, which is included in the statistical software $\mathrm{R}$ version 3.1.3.

\section{Results}

\section{Outcomes of MCS/SCS}

Table 3 shows the outcomes of the trial and the long-term effects of MCS and SCS. In the 15 patients implanted with MCS electrodes, 11 (73.3\%) had a trial success. Eight of the 11 patients who were implanted with the MCS and IPG system achieved successful long-term effects. During the mean followup period of $105.4 \pm 41.9$ months, eight out of 15 $(53.3 \%)$ patients achieved successful long-term effects overall. All eight patients achieving long-term effects continued the effect for more than 2 years. In the 35 patients implanted with the SCS electrodes, $27(77.1 \%)$ had a trial success. Twenty of the 27 patients who were implanted with the SCS and
Table 3 Motor cortex and spinal cord stimulation outcomes and details

\begin{tabular}{|c|c|c|}
\hline & $\operatorname{MCS}(n=15)$ & $\operatorname{SCS}(n=35)$ \\
\hline \multicolumn{3}{|l|}{ Location of lesion } \\
\hline $\begin{array}{l}\text { Total trial success } \\
\text { (rate) }\end{array}$ & $11 / 15(73.3 \%)$ & $27 / 35(77.1 \%)$ \\
\hline Brain & 7/9 (77.8\%) & $12 / 18(66.7 \%)$ \\
\hline Spine & $2 / 2(100 \%)$ & $4 / 4(100 \%)$ \\
\hline Peripheral & $2 / 3(66.7 \%)$ & $11 / 13(84.6 \%)$ \\
\hline $\begin{array}{l}\text { Total long-term effect } \\
\text { (rate) }\end{array}$ & 8/15 (53.3\%) & $20 / 35(57.1 \%)$ \\
\hline Brain & $4 / 9(44.4 \%)$ & $8 / 18(44.4 \%)$ \\
\hline Spine & $2 / 2(100 \%)$ & $3 / 4(75 \%)$ \\
\hline Peripheral & $2 / 3(66.7 \%)$ & $9 / 13(69.2 \%)$ \\
\hline \multicolumn{3}{|l|}{ Causes of pain } \\
\hline \multicolumn{3}{|l|}{ Trial success (rate) } \\
\hline CPSP & $6 / 9(66.7 \%)$ & $11 / 17(64.7 \%)$ \\
\hline SCI pain & $2 / 2(100 \%)$ & $4 / 4(100 \%)$ \\
\hline FBSS & - & $7 / 7(100 \%)$ \\
\hline CRPS type I & - & $1 / 1(100 \%)$ \\
\hline \multicolumn{3}{|l|}{$\begin{array}{l}\text { Long-term effect } \\
\text { (rate) }\end{array}$} \\
\hline CPSP & $3 / 9(33.3 \%)$ & $7 / 17(41.2 \%)$ \\
\hline SCI pain & $2 / 2(100 \%)$ & $3 / 4(75 \%)$ \\
\hline FBSS & - & $5 / 7(71.4 \%)$ \\
\hline CRPS type I & - & $1 / 1(100 \%)$ \\
\hline
\end{tabular}

CPSP: central poststroke pain, CRPS: complex regional pain syndrome, FBSS: failed back surgery syndrome, MCS: motor cortex stimulation, SCI: spinal cord injury, SCS: spinal cord stimulation.

IPG system achieved successful long-term effects. During the mean follow-up period of $44.8 \pm 26.3$ months, 20 out of $35(57.1 \%)$ patients achieved successful long-term effects overall. Fourteen out of 20 patients achieving long-term effects continued the effect for more than 2 years. There were no MCS or SCS patients who required removal of the system due to infection.

\section{Relationship between the location of lesion and long-term effect of MCS/SCS}

The respective long-term effect rates for the MCS and SCS in accordance with the location of lesion were $44.4 \%(4 / 9)$ and $44.4 \%$ (8/18) for the brain, $100 \%$ $(2 / 2)$ and $75 \%(3 / 4)$ for the spine, and $66.7 \%(2 / 3)$ and $69.2 \%(9 / 13)$ for the peripheral nerves (Table 3$)$. There was no statistical relationship observed between the long-term effect of MCS/SCS and the location of lesion. The respective long-term effect rates for the MCS and SCS in accordance with the cause of pain 
were $33.3 \%(3 / 9)$ and $41.2 \%(7 / 17)$ for CPSP, $100 \%$ $(2 / 2)$ and $75 \%(3 / 4)$ for SCI, $71.4 \%(5 / 7)$ for FBSS in SCS, and $100 \%(1 / 1)$ for CRPS type I in SCS (Table 3).

Predictive factors of the long-term effect of MCS/SCS

Tables 4 and 5 show the comparisons of the characteristics for MCS and SCS among the longterm effect, no long-term effect, and no trial success groups, respectively. No statistical differences were observed for the age, sex, duration of pain, location of lesion, sensory disturbance, motor weakness, site of pain, laterality of pain, and preoperative VAS scores among the three groups for both MCS and SCS. Interestingly, there were statistical differences in the VAS scores at 1 and 6 months after the surgery between the long-term effect group and the no longterm effect group for both MCS and SCS $(P<0.05)$. Figure 1 shows the scatter graph for the PPR at 1 month after SCS implantation versus the length

Table 4 Comparison of characteristics among the groups for the long-term effect, no long-term effect, and no trial success for motor cortex stimulation

\begin{tabular}{|c|c|c|c|c|}
\hline & Long-term effect & No long-term effect & No trial success & $P$-value \\
\hline Number & 8 & 3 & 4 & \\
\hline Age & $52.9 \pm 16.9$ & $63.3 \pm 5.9$ & $57.0 \pm 9.5$ & 0.5535 \\
\hline $\operatorname{Sex}(M / F)$ & $3 / 5$ & $2 / 1$ & $4 / 0$ & 0.1133 \\
\hline Duration of pain (years) & $4.4 \pm 2.8$ & $3.3 \pm 1.5$ & $2.0 \pm 0.8$ & 0.261 \\
\hline \multicolumn{5}{|l|}{ Location of lesion } \\
\hline (Brain/spine/peripheral) & $4 / 2 / 2$ & $3 / 0 / 0$ & $3 / 0 / 1$ & 0.6643 \\
\hline \multicolumn{5}{|l|}{ Sensory disturbance } \\
\hline Hypoesthesia & 8 & 3 & 4 & 1 \\
\hline Allodynia & 5 & 0 & 2 & 0.3082 \\
\hline \multicolumn{5}{|l|}{ Motor weakness } \\
\hline (Minimal/moderate + severe) & $2 / 1$ & $3 / 0$ & $2 / 2$ & 0.06636 \\
\hline Site of pain & & & & 0.4409 \\
\hline $\mathrm{UE}$ & 2 & 0 & 1 & \\
\hline $\mathrm{LE}$ & 0 & 1 & 0 & \\
\hline $\mathrm{UE}+\mathrm{LE}$ & 3 & 2 & 3 & \\
\hline Face & 3 & 0 & 0 & \\
\hline \multicolumn{5}{|l|}{ Laterality of pain } \\
\hline Bilateral/left/right & $1 / 3 / 4$ & $0 / 0 / 3$ & $0 / 1 / 3$ & 0.8657 \\
\hline \multicolumn{5}{|l|}{ VAS } \\
\hline Preop. & $9.3 \pm 1.2$ & $9.3 \pm 1.2$ & $8.5 \pm 1.7$ & 0.6182 \\
\hline $1 \mathrm{~m}$ & $3.0 \pm 0.9$ & $6.3 \pm 1.2$ & - & $0.01212^{\mathrm{a}}$ \\
\hline $6 \mathrm{~m}$ & $3.9 \pm 1.8$ & $7.3 \pm 0.6$ & - & $0.0303^{\mathrm{a}}$ \\
\hline $12 \mathrm{~m}$ & $4.3 \pm 1.7$ & - & - & - \\
\hline Last & $4.3 \pm 1.7$ & - & - & - \\
\hline PPR (\%) & & & - & \\
\hline $1 \mathrm{~m}$ & $67.1 \pm 11.0$ & $30.8 \pm 18.8$ & - & - \\
\hline $6 \mathrm{~m}$ & $57.7 \pm 20.1$ & $20.0 \pm 17.3$ & - & - \\
\hline $12 \mathrm{~m}$ & $54.3 \pm 16.4$ & - & - & - \\
\hline Last & $54.3 \pm 16.4$ & - & - & - \\
\hline
\end{tabular}

F: female, Last: last follow-up, LE: lower extremity, m: month, M: male, PPR: percentage of pain relief, Preop.: preoperative, UE: upper extremity, VAS: visual analog scale, ${ }^{a}$ Statistically significant. 
Table 5 Comparison of characteristics among the groups for the long-term effect, no long-term effect, and no trial success for spinal cord stimulation

\begin{tabular}{|c|c|c|c|c|}
\hline & Long-term effect & No long-term effect & No trial success & $P$-value \\
\hline Number & 20 & 7 & 8 & \\
\hline Age & $61.3 \pm 13.9$ & $67.1 \pm 8.1$ & $65.5 \pm 10.6$ & 0.4835 \\
\hline $\operatorname{Sex}(M / F)$ & $9 / 11$ & $5 / 2$ & $4 / 4$ & 0.5846 \\
\hline Duration of pain (yrs) & $4.4 \pm 3.9$ & $4.1 \pm 3.0$ & $4.6 \pm 4.3$ & 0.9705 \\
\hline \multicolumn{5}{|l|}{ Location of lesion } \\
\hline (Brain/spine/peripheral) & $8 / 3 / 9$ & $4 / 1 / 2$ & $6 / 0 / 2$ & 0.5604 \\
\hline \multicolumn{5}{|l|}{ Sensory disturbance } \\
\hline Hypoesthesia & 10 & 6 & 5 & 0.2618 \\
\hline Allodynia & 11 & 4 & 6 & 0.6468 \\
\hline \multicolumn{5}{|l|}{ Motor weakness } \\
\hline (Minimal/moderate + severe) & $3 / 5$ & $2 / 2$ & $3 / 1$ & 0.6993 \\
\hline Site of pain & & & & 0.7235 \\
\hline $\mathrm{UE}$ & 3 & 2 & 0 & \\
\hline $\mathrm{LE}$ & 6 & 1 & 2 & \\
\hline $\mathrm{UE}+\mathrm{LE}$ & 5 & 3 & 5 & \\
\hline Lumbar & 2 & 1 & 0 & \\
\hline Lumbar + LE & 3 & 0 & 1 & \\
\hline Other & 1 & 0 & 0 & \\
\hline \multicolumn{5}{|l|}{ Laterality of pain } \\
\hline Bilateral/left/right & $8 / 10 / 2$ & $3 / 1 / 3$ & $1 / 3 / 4$ & 0.09163 \\
\hline \multicolumn{5}{|l|}{ VAS } \\
\hline Preop. & $8.3 \pm 1.7$ & $8.3 \pm 1.5$ & $8.5 \pm 0.5$ & 0.9309 \\
\hline $1 \mathrm{~m}$ & $2.8 \pm 2.2$ & $5.6 \pm 1.6$ & - & $0.00637^{\mathrm{a}}$ \\
\hline $6 \mathrm{~m}$ & $3.1 \pm 2.3$ & $7.6 \pm 0.6$ & - & $0.001694^{\mathrm{a}}$ \\
\hline $12 \mathrm{~m}$ & $3.5 \pm 2.6$ & 8 & - & - \\
\hline Last & $3.3 \pm 2.4$ & - & - & - \\
\hline \multicolumn{5}{|l|}{ PPR (\%) } \\
\hline $1 \mathrm{~m}$ & $67.6 \pm 21.2$ & $32.8 \pm 16.2$ & - & - \\
\hline $6 \mathrm{~m}$ & $64.7 \pm 22.1$ & $10.8 \pm 10.1$ & - & - \\
\hline $12 \mathrm{~m}$ & $60.4 \pm 25.4$ & 20 & - & - \\
\hline Last & $62.3 \pm 23.4$ & - & - & - \\
\hline
\end{tabular}

F: female, Last: last follow-up, LE: lower extremity, m: month, M: male, PPR: percentage of pain relief, Preop.: preoperative, UE: upper extremity, VAS: visual analog scale, a Statistically significant.

of the continuing SCS effect. The cut-off value of the PPR at 1 month after SCS implantation versus the length of the continuing SCS effect was 50\%, with a sensitivity of $100 \%$ and specificity of $75 \%$.

\section{Comparison between excellent and good groups of MCS/SCS}

The rates of excellent outcome at the time of the last follow-up were $37.5 \%$ (3/8) in MCS and 45.0\%
(9/20) in SCS patients. There were no statistical differences for the preoperative characteristics between the excellent and good groups in both the MCS and SCS patients. Figure 2 shows the changes in the VAS scores of the excellent and good groups at 1 month after the surgery in MCS and SCS patients (a: MCS, b: SCS). There were several common findings between the MCS and SCS groups. The VAS scores of the excellent groups at 1 month after 
the surgery remained low from 1 month after the surgery until the time of the last follow-up. And, no patients with excellent groups at 1 month after surgery in both MCS and SCS, were removed the implantation system during follow up periods. In contrast, the VAS scores of the good groups at 1 month after the surgery exhibited a significant increase at 6 months after surgery compared to that seen at 1 month. In patients with good groups at 1 month after surgery, the implantation systems

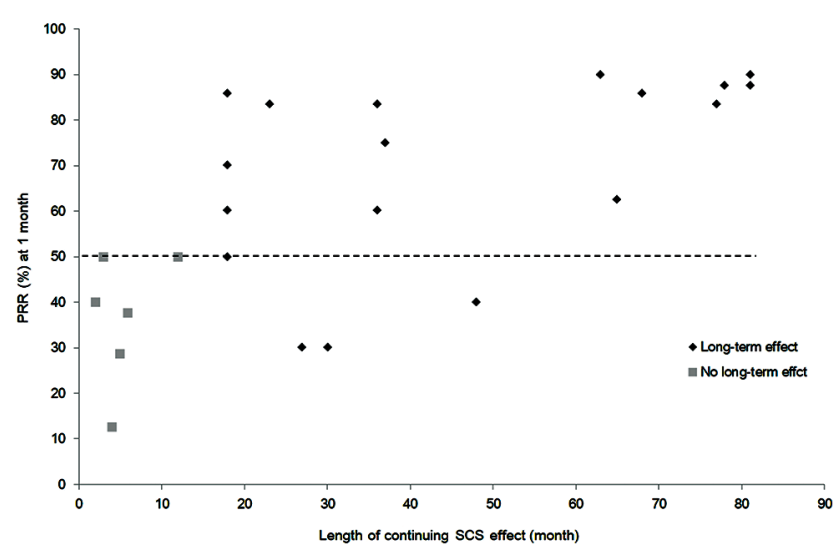

Fig. 1 Cut-off value of the percentage of pain relief at 1 month after SCS. Scatter graph shows the relationship of the percentage of pain relief (PPR) at 1 month after SCS surgery versus the length of the SCS effect. The black diamonds and gray squares indicate patients with a continuing SCS effect over 12 months (long-term effect) and patients with a SCS effect less than 12 months (no long-term effect), respectively. The dotted line indicates the cut-off value line for the PPR at 1 month after surgery. This line divides the long-term effect from the no long-term effect. The cut-off value is $50 \%$, with a sensitivity of $100 \%$ and a specificity of $75 \%$. were removed in the 50.0\% (3/6) in MCS and 58.3\% $(7 / 12)$ in SCS patients.

\section{Discussion}

A previous review of the efficacy of MCS has reported that $57.6 \%$ of the examined patients overall had more than $40-50 \%$ pain relief. ${ }^{5)}$ There have been several reports of the long-term effects of MCS with more than 3.5 years of follow-up. ${ }^{14,26-28)} \mathrm{Im}$ et al. examined 21 patients with neuropathic pain who underwent MCS, and reported that the trial success rate was $76.2 \%$, with long-term effects achieved in $52.4 \%$ during $53 \pm 39$ months of follow-up. ${ }^{26)}$ These results are compatible with our current findings. Predictive factors associated with long-term effects of MCS are still unclear. Several previous studies have reported that preoperative characteristics of patients such as the age, sex, and duration of pain, among others, were not related to the long-term outcomes. ${ }^{14,26-28)}$ However, the level of pain relief at 1 month after MCS system implantation was reported to be a strong predictor of long-term relief. ${ }^{27)}$ This result indicates that in the no long-term effect group, the initial pain relief might reflect the placebo effects. Thus, in order to achieve a long-term effect, this suggests that it is necessary to separate out these types of patients during the trial period. Rasche et al. investigated the use of MCS in 17 patients with chronic neuropathic pain. ${ }^{14)}$ Note is the fact that there were no patients who exhibited vanishing effects during the follow-up. The test stimulation in this series was double-blind. In other words, real or placebo stimulations were performed after blinding of the patients and physicians, with all of the stimulation parameters controlled and programmed by an
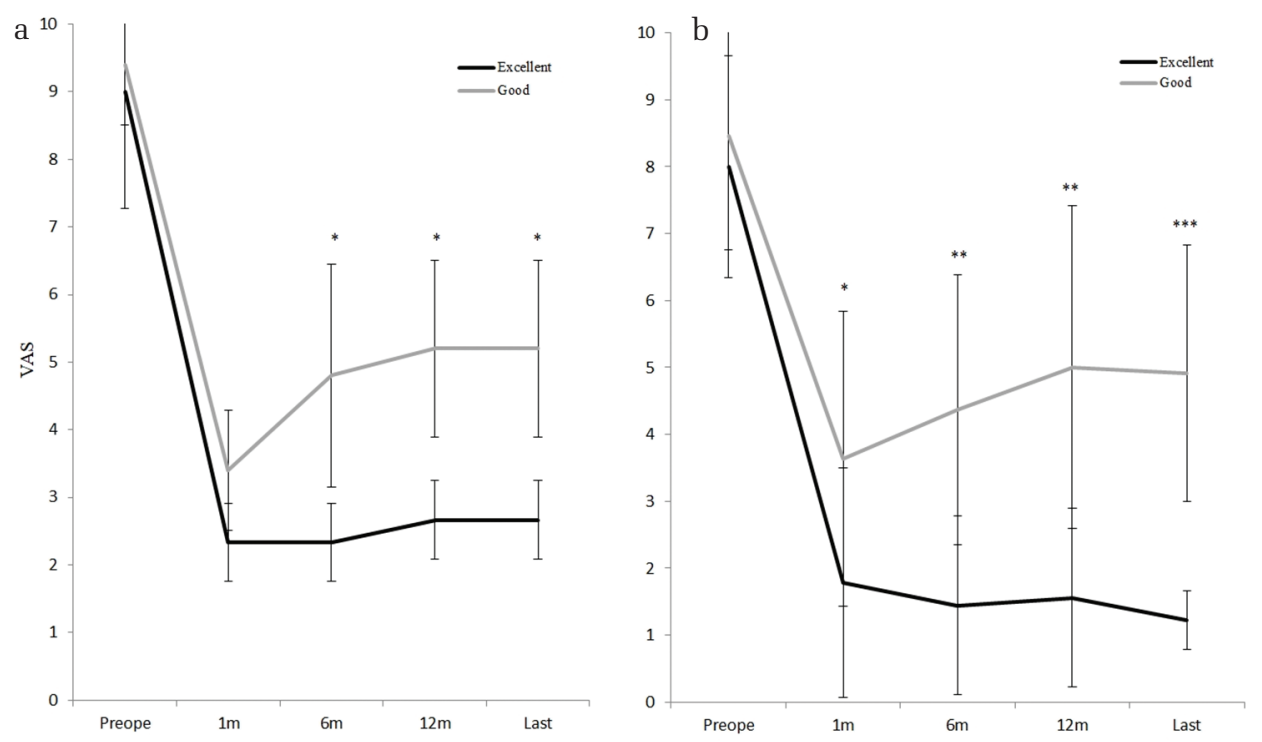

Fig. 2 Comparison between excellent and good groups of MCS/SCS. Line graphs show the changes of the average VAS scores and the standard deviation of the excellent and good groups for MCS (a) and SCS (b). The black and gray lines indicate the excellent and good groups, respectively. There were no statistically significant differences between the VAS scores at baseline for both the MCS and SCS. After 6 months, however, the VAS scores of the good groups significantly increased as compared to the excellent groups $\left({ }^{*} P<0.05\right.$, ${ }^{*} P$ $<0.001$ ). 
independent physician. Double-blinded stimulations are considered to be able to discriminate patients who may have placebo effects.

FBSS and CRPS type I have been suggested to be pain types that can be treated by SCS. ${ }^{29,30)}$ Percentages found for long-term effects in patients who have been subjected to more than 12 months of FBSS and CRPS type I were reported to be $60-70 \%$ and $63-72 \%$, respectively. ${ }^{17,31,32)}$ In our current series, the total rate for the long-term effect of SCS was $57.1 \%$, with this rate affected by the proportion of the number of FBSS and CRPS type I in the patient groups. In our study, $23 \%$ of the total patients were FBSS and CRPS type I, while 63\% had central neuropathic pain. Although the percentage for the long-term effects of SCS for peripheral origin pain was $69.2 \%$, which was higher than for the brain origin pain $(44.4 \%)$, there was no statistical difference between the two locations. The reason for this result is likely that SCS for CPSP had a comparatively high rate of long-term effects in our series. Although SCS has not been recommended for the treatment of central neuropathic pain, ${ }^{29,30)}$ it has been recently reported that some CPSP patients have been successfully treated by SCS. ${ }^{33,34)}$

Relationships of site of pain and efficacy of MCS were reported that upper extremity or face pain were easy to treat because of more easily localizing the epidural electrode array on the representation of the pain sites in the motor cortex. ${ }^{14)}$ SCS was more efficacy for lower extremity or lumbar pain. ${ }^{17,31)}$ In our study, rates of long-term effects were $100 \%(3 / 3)$ of facial pain and $66.7 \%(2 / 3)$ of upper extremity pain in MCS, and $66.7 \%(6 / 9)$ of lower extremity pain and $75 \%(3 / 4)$ of both lower extremity and lumbar pain in SCS. However, there were no statistical difference between site of pain and efficacy of MCS/SCS. The reasons for this result were small number of MCS for lower extremity pain (1) and SCS for upper extremity (5), and SCS was not indicated facial pain.

Although several predictive factors associated with long-term effects of SCS have been reported, this remains controversial. ${ }^{17,35-39)}$ Psychological factors are commonly known to influence the effect of SCS. ${ }^{40)}$ Systemic reviews have suggested that psychological factors such as somatization, depression, and anxiety are predictive factors of the poor performance of SCS. ${ }^{36,37)}$ Although we did not perform meticulous preoperative evaluations of the psychological conditions or double-blinded test stimulations in our series, we did find that values of the PPR at 1 month after the surgery might be a useful postoperative predictor of the long-term effect. The cut-off value for achieving the long-term effect of SCS was shown to be $50 \%$ of the PPR at 1 month after the surgery. Moreover, a sensitivity of $100 \%$ indicates that all patients will achieve long-term effects when the PPR at 1 month after surgery is higher than $50 \%$. A specificity of $75 \%$ indicates that $75 \%$ of patients will not achieve the long-term effects when the PPR at 1 month after surgery is less than $50 \%$.

There were similar finding for both the MCS and SCS, such as excellent groups at 1 month after the surgery remained the effect until the time of the last follow-up, and good groups at 1 month after the surgery exhibited a significant decrease in the effects at 6 months after surgery. We speculated that the similar features observed for MCS and SCS might imply a common underlying mechanism for pain relief. Neuroimaging studies have shown a significant correlation between the analgesic effect of MCS and the regional cerebral blood flow (rCBF) changes in various regions including the anterior cingulate gyrus, orbitofrontal cortex, thalamus, anterior insula, and brain stem. ${ }^{4-45)}$ SCS also induces changes of activity in the anterior cingulate cortex and thalamus, which can be identified by increases and decreases in the $\mathrm{rCBF}^{46)}$ Previous neuroimaging studies have indicated that SCS induced modulations in the somatosensory and emotional areas of the brain. ${ }^{4-50)}$ Therefore, the common modulations of the pain matrix induced by electrical stimulation may be one reason for the similar features observed for MCS and SCS.

\section{Conclusion}

For non-selected patients with chronic neuropathic pain who did not undergo the double-blind test stimulation method, rates of the long-term effect of MCS and SCS were approximately 50\% during the more than 8.5 and 3.5 years of follow-up, respectively. Although it remains unclear as to the preoperative predictive factors for the long-term effects, the VAS at 1 month after surgery may be a postoperative predictor of the long-term effects for both MCS and SCS. The cut-off value for achieving the long-term effect of SCS was shown to be $50 \%$ of the PPR at 1 month after the surgery. In order to increase the rates of the long-term effect for both MCS and SCS, it is necessary to select appropriate patients prior to the surgery and exclude those patients who demonstrate placebo effects during the trial period. Similar features were detected, such as excellent groups at 1 month after the surgery remained the effect until the time of the last follow-up in both 
MCS and SCS. This may reflect a common mechanism for pain relief. The limitations of our studies were the retrospective design and the small sample size. Prospective controlled studies with large sample sizes will need to be undertaken in order to provide further evidence.

\section{Conflicts of Interest Disclosure}

All authors certify that they have no affiliations with or involvement in any organization or entity with any financial interest (e.g., honoraria; educational grants; participation in speakers' bureaus; membership, employment, consultancies, stock ownership, or other equity interest; and expert testimony or patent-licensing arrangements) or non-financial interest (e.g., personal or professional relationships, affiliations, knowledge, or beliefs) in the subject matter or materials discussed in this manuscript.

\section{Informed Consent}

Informed consent was obtained from all individual participants included in the study.

\section{References}

1) Zhang TC, Janik JJ, Grill WM: Mechanisms and models of spinal cord stimulation for the treatment of neuropathic pain. Brain Res 1569: 19-31, 2014

2) Tsubokawa T, Katayama Y, Yamamoto T, Hirayama T, Koyama S: Chronic motor cortex stimulation for the treatment of central pain. Acta Neurochir Suppl (Wien) 52: 137-139, 1991

3) Tsubokawa T, Katayama Y, Yamamoto T, Hirayama T, Koyama S: Chronic motor cortex stimulation in patients with thalamic pain. J Neurosurg 78: 393-401, 1993

4) Drouot X, Nguyen JP, Peschanski M, Lefaucheur JP: The antalgic efficacy of chronic motor cortex stimulation is related to sensory changes in the painful zone. Brain 125: 1660-1664, 2002

5) Fontaine D, Hamani C, Lozano A: Efficacy and safety of motor cortex stimulation for chronic neuropathic pain: critical review of the literature. J Neurosurg 110: 251-256, 2009

6) Lazorthes Y, Sol JC, Fowo S, Roux FE, Verdié JC: Motor cortex stimulation for neuropathic pain. Acta Neurochir Suppl 97: 37-44, 2007

7) Meyerson BA, Lindblom U, Linderoth B, Lind G, Herregodts P: Motor cortex stimulation as treatment of trigeminal neuropathic pain. Acta Neurochir Suppl (Wien) 58: 150-153, 1993

8) Monsalve GA: Motor cortex stimulation for facial chronic neuropathic pain: a review of the literature. Surg Neurol Int 3: S290-S311, 2012
9) Nguyen JP, Keravel Y, Feve A, et al.: Treatment of deafferentation pain by chronic stimulation of the motor cortex: report of a series of 20 cases. Acta Neurochir Suppl 68: 54-60, 1997

10) Nguyen JP, Lefaucher JP, Le Guerinel C, et al.: Motor cortex stimulation in the treatment of central and neuropathic pain. Arch Med Res 31: 263-265, 2000

11) Velasco M, Velasco F, Brito F, et al.: Motor cortex stimulation in the treatment of deafferentation pain. I. Localization of the motor cortex. Stereotact Funct Neurosurg 79: 146-167, 2002

12) Lefaucheur JP, Drouot X, Cunin P, et al.: Motor cortex stimulation for the treatment of refractory peripheral neuropathic pain. Brain 132: 1463-1471, 2009

13) Nguyen JP, Velasco F, Brugières P, et al.: Treatment of chronic neuropathic pain by motor cortex stimulation: results of a bicentric controlled crossover trial. Brain Stimul 1: 89-96, 2008

14) Rasche D, Ruppolt M, Stippich C, Unterberg A, Tronnier VM: Motor cortex stimulation for longterm relief of chronic neuropathic pain: a 10 year experience. Pain 121: 43-52, 2006

15) Velasco F, Argüelles C, Carrillo-Ruiz JD, et al.: Efficacy of motor cortex stimulation in the treatment of neuropathic pain: a randomized double-blind trial. J Neurosurg 108: 698-706, 2008

16) Deer TR, Mekhail N, Provenzano D, et al.; Neuromodulation Appropriateness Consensus Committee: The appropriate use of neurostimulation of the spinal cord and peripheral nervous system for the treatment of chronic pain and ischemic diseases: the Neuromodulation Appropriateness Consensus Committee. Neuromodulation 17: 515-550, 2014

17) Kumar K, Hunter G, Demeria D: Spinal cord stimulation in treatment of chronic benign pain: challenges in treatment planning and present status, a 22-year experience. Neurosurgery 58: 481-496, 2006

18) Holsheimer J, Nuttin B, King GW, Wesselink WA, Gybels JM, de Sutter P: Clinical evaluation of paresthesia steering with a new system for spinal cord stimulation. Neurosurgery 42: 541-547; discussion 547-549, 1998

19) Rainov NG, Demmel W, Heidecke V: Dual electrode spinal cord stimulation in chronic leg and back pain. Acta Neurochir Suppl 97: 85-89, 2007

20) Kumar K, Taylor RS, Jacques L, et al.: Spinal cord stimulation versus conventional medical management for neuropathic pain: a multicentre randomised controlled trial in patients with failed back surgery syndrome. Pain 132: 179-188, 2007

21) North RB, Kidd DH, Farrokhi F, Piantadosi SA: Spinal cord stimulation versus repeated lumbosacral spine surgery for chronic pain: a randomized, controlled trial. Neurosurgery 56: 98-106; discussion 106-107, 2005

22) Kemler MA, Barendse GA, van Kleef M, et al.: Spinal cord stimulation in patients with chronic reflex sympathetic dystrophy. $N$ Engl $J$ Med 343: 618-624, 2000 
23) de Vos CC, Meier K, Zaalberg PB, et al.: Spinal cord stimulation in patients with painful diabetic neuropathy: a multicentre randomized clinical trial. Pain 155: 2426-2431, 2014

24) Slangen R, Schaper NC, Faber CG, et al.: Spinal cord stimulation and pain relief in painful diabetic peripheral neuropathy: a prospective two-center randomized controlled trial. Diabetes Care 37: 3016-3024, 2014

25) de Jongste MJ, Hautvast RW, Hillege HL, Lie KI: Efficacy of spinal cord stimulation as adjuvant therapy for intractable angina pectoris: a prospective, randomized clinical study. Working Group on Neurocardiology. J Am Coll Cardiol 23: 1592-1597, 1994

26) Im SH, Ha SW, Kim DR, Son BC: Long-term results of motor cortex stimulation in the treatment of chronic, intractable neuropathic pain. Stereotact Funct Neurosurg 93: 212-218, 2015

27) Nuti C, Peyron R, Garcia-Larrea L, et al.: Motor cortex stimulation for refractory neuropathic pain: four year outcome and predictors of efficacy. Pain 118: 43-52, 2005

28) Sokal P, Harat M, Zieliński P, Furtak J, Paczkowski D, Rusinek M: Motor cortex stimulation in patients with chronic central pain. Adv Clin Exp Med 24: 289-296, 2015

29) Cruccu G, Aziz TZ, Garcia-Larrea L, et al.: EFNS guidelines on neurostimulation therapy for neuropathic pain. Eur J Neurol 14: 952-970, 2007

30) Dworkin RH, O'Connor AB, Kent J, et al.; International Association for the Study of Pain Neuropathic Pain Special Interest Group: Interventional management of neuropathic pain: NeuPSIG recommendations. Pain 154: 2249-2261, 2013

31) Gatzinsky K, Baardsen R, Buschman HP: Evaluation of the effectiveness of percutaneous octapolar leads in pain treatment with spinal cord stimulation of patients with failed back surgery syndrome during a 1-year follow-up: a prospective multicenter international study. Pain Pract 17: 428-437, 2017

32) Geurts JW, Smits H, Kemler MA, Brunner F, Kessels AG, van Kleef M: Spinal cord stimulation for complex regional pain syndrome type I: a prospective cohort study with long-term follow-up. Neuromodulation 16: 523-529, 2013

33) Aly MM, Saitoh Y, Hosomi K, Oshino S, Kishima H, Yoshimine T: Spinal cord stimulation for central poststroke pain. Neurosurgery 67: ons206-ons212, 2010

34) Yamamoto T, Watanabe M, Obuchi T, et al.: Importance of pharmacological evaluation in the treatment of poststroke pain by spinal cord stimulation. Neuromodulation 19: 744-751, 2016

35) Burchiel KJ, Anderson VC, Wilson BJ, Denison DB, Olson KA, Shatin D: Prognostic factors of spinal cord stimulation for chronic back and leg pain. Neurosurgery 36: 1101-1110; discussion 1110-1111, 1995
36) Celestin J, Edwards RR, Jamison RN: Pretreatment psychosocial variables as predictors of outcomes following lumbar surgery and spinal cord stimulation: a systematic review and literature synthesis. Pain Med 10: 639-653, 2009

37) Sparkes E, Raphael JH, Duarte RV, LeMarchand K, Jackson C, Ashford RL: A systematic literature review of psychological characteristics as determinants of outcome for spinal cord stimulation therapy. Pain 150: 284-289, 2010

38) Sparkes E, Duarte RV, Mann S, Lawrence TR, Raphael JH: Analysis of psychological characteristics impacting spinal cord stimulation treatment outcomes: a prospective assessment. Pain Physician 18: E369-E377, 2015

39) Taylor RS, Desai MJ, Rigoard P, Taylor RJ: Predictors of pain relief following spinal cord stimulation in chronic back and leg pain and failed back surgery syndrome: a systematic review and meta-regression analysis. Pain Pract 14: 489-505, 2014

40) Doleys DM: Psychological factors in spinal cord stimulation therapy: brief review and discussion. Neurosurg Focus 21: E1, 2006

41) García-Larrea L, Peyron R, Mertens P, et al.: Electrical stimulation of motor cortex for pain control: a combined PET-scan and electrophysiological study. Pain 83: 259-273, 1999

42) Garcia-Larrea L, Maarrawi J, Peyron R, et al.: On the relation between sensory deafferentation, pain and thalamic activity in Wallenberg's syndrome: a PET-scan study before and after motor cortex stimulation. Eur J Pain 10: 677-688, 2006

43) Peyron R, Garcia-Larrea L, Deiber MP, et al.: Electrical stimulation of precentral cortical area in the treatment of central pain: electrophysiological and PET study. Pain 62: 275-286, 1995

44) Peyron R, Faillenot I, Mertens P, Laurent B, Garcia-Larrea L: Motor cortex stimulation in neuropathic pain. Correlations between analgesic effect and hemodynamic changes in the brain. A PET study. Neuroimage 34: 310-321, 2007

45) Saitoh Y, Osaki Y, Nishimura H, et al.: Increased regional cerebral blood flow in the contralateral thalamus after successful motor cortex stimulation in a patient with poststroke pain. J Neurosurg 100: 935-939, 2004

46) Bentley LD, Duarte RV, Furlong PL, Ashford RL, Raphael JH: Brain activity modifications following spinal cord stimulation for chronic neuropathic pain: a systematic review. Eur J Pain 20: 499-511, 2016

47) Kishima H, Saitoh Y, Oshino S, et al.: Modulation of neuronal activity after spinal cord stimulation for neuropathic pain; H(2)15O PET study. Neuroimage 49: $2564-2569,2010$

48) Moens M, Sunaert S, Mariën P, et al.: Spinal cord stimulation modulates cerebral function: an fMRI study. Neuroradiology 54: 1399-1407, 2012 
49) Peppucci E, Di Bonaventura R, Esposito V, et al.: Update on mechanism and therapeutic implications of spinal cord stimulation and cerebral hemodynamics: a narrative review. Acta Neurochir Suppl 124: 27-36, 2017

50) Stancák A, Kozák J, Vrba I, et al.: Functional magnetic resonance imaging of cerebral activation during spinal cord stimulation in failed back surgery syndrome patients. Eur J Pain 12: 137-148, 2008

Address reprint requests to: Takafumi Tanei, $\mathrm{MD}, \mathrm{PhD}$, Department of Neurosurgery, Komaki City Hospital, 1-20 Jobushi, Komaki, Aichi 485-8520, Japan. e-mail: nsgtakasyun@msn.com 